\title{
Lessons of the month: A challenging presentation of hypopituitarism secondary to an intracerebral aneurysm
}

\author{
Authors: Emma M Mullarkey, ${ }^{A}$ Ashok Iyer $^{B}$ and Ajibola Ihuoma ${ }^{B}$
}

\section{A 65-year-old man presented to ambulatory care with a} 10-month history of muscle weakness, weight loss, dysphagia and fatigue.

Prior to presentation he had been managed in general practice for hypothyroidism with a low T4 level and normal thyroid stimulation hormone (TSH). He was commenced on levothyroxine yet, despite dose titrations, had ongoing symptoms. He had been extensively reviewed by gastroenterology and rheumatology teams.

The thyroid function tests (TFTs) pattern prompted a pituitary hormone profile test, which revealed panhypopituitarism with a cortisol of $22 \mathrm{nmol} / \mathrm{L}$. Therefore, hydrocortisone was commenced. A pituitary magnetic resonance imaging (MRI) detected a left internal carotid aneurysm that was confirmed on computed tomography angiography. He successfully underwent embolisation of the aneurysm in the local neurosurgical centre.

This case highlights the importance of correctly interpreting TFTs as this patient's initial TFTs indicated central hypothyroidism which should have prompted urgent pituitary hormone screening. The risk of addisonian crisis with commencement of levothyroxine without steroid replacement in secondary hypothyroidism emphasises the importance of TFT interpretation. Internal carotid artery aneurysms are a rare, yet important, cause of hypopituitarism resulting in high mortality and morbidity associated with delayed diagnosis secondary to the pressure effects of the aneurysm or the effects of aneurysmal rupture.

KEYWORDS: hypopituitarism, intracranial aneurysm, secondary hypothyroidism

DOI: 10.7861/clinmed.2020-1017

\section{Case presentation}

A 65-year-old man presented to ambulatory care with a 10-month history of muscle weakness, fatigue, weight loss and dysphagia.

Authors: ${ }^{\text {A }}$ linical fellow, Chelsea and Westminster Hospital, London, UK; ${ }^{\mathrm{B}}$ consultant in acute medicine, University Hospital Lewisham, Lewisham, UK
He initially described lethargy before developing muscle weakness which progressively worsened. He had intermittent dysphagia with solids and liquids and was increasingly finding it difficult to do routine activities due to muscle weakness, pain and fatigue. He had hot flushes, emotional lability and a reduced appetite with weight loss of 5 stone. He denied headaches or visual changes.

He has a past medical history of hypertension, hyperlipidaemia and obstructive sleep apnoea, with home continuous positive airway pressure (CPAP). His regular medications were losartan, atorvastatin and levothyroxine.

Prior to presentation, he was managed in primary care from the onset of symptoms and was treated for hypothyroidism. Despite commencing and uptitrating levothyroxine, his symptoms did not diminish. Table 1 indicates his thyroid function tests (TFTs) and corresponding levothyroxine dose.

He had been referred to gastroenterology and had a normal oesophago-gastro-duodenoscopy and computed tomography (CT) of the chest, abdomen and pelvis. He was reviewed by rheumatology. His creatinine kinase was mildly elevated at $212 \mathrm{U} / \mathrm{L}$ with normal inflammatory markers. He had a negative autoantibody, viral screen and normal protein electrophoresis. His CT positron emission tomography (PET) was unremarkable.

The main findings on examination were proximal myopathy in upper and lower limbs with associated tenderness. His reflexes and sensation were normal. His cardiorespiratory, dermatology and abdominal examination was unremarkable.

In view of the history, negative investigations and TFT pattern, a pituitary profile was requested (Table 2). He was diagnosed with panhypopituitarism and promptly commenced on hydrocortisone.

He had a pituitary magnetic resonance imaging (MRI) which was suggestive of a vascular lesion. This was confirmed on CT angiography as a left cavernous internal carotid artery aneurysm (Fig 1).

\section{Outcome}

He was transferred to a neurosurgical centre and had embolisation of this aneurysm. He was reviewed pre- and postoperatively by ophthalmology and had no visual field defect.

He was discharged 3 days after this procedure with neurosurgical and endocrine follow-up.

He remains on levothyroxine and steroid replacement therapy. He commenced dual antiplatelet therapy and testosterone.

Given the long-term effects of hypogonadism, he had dualenergy $X$-ray absorptiometry (DEXA) which indicated osteopenia with a calculated T score of -1.2 (spine) and 0.3 (left hip). His 
Table 1. Thyroid Function tests and dose of levothyroxine

\begin{tabular}{llllllll} 
& $\begin{array}{l}\text { November } \\
\mathbf{2 0 1 8}\end{array}$ & $\begin{array}{l}\text { December } \\
\mathbf{2 0 1 8}\end{array}$ & $\begin{array}{l}\text { February } \\
\mathbf{2 0 1 9}\end{array}$ & $\begin{array}{l}\text { March } \\
\mathbf{2 0 1 9}\end{array}$ & $\begin{array}{l}\text { May } \\
\mathbf{2 0 1 9}\end{array}$ & $\begin{array}{l}\text { June } \\
\mathbf{2 0 1 9}\end{array}$ & $\begin{array}{l}\text { August 2019 (first } \\
\text { presentation to ACU) }\end{array}$ \\
$\begin{array}{l}\text { T3, pmol/L (normal } \\
\text { range 3.1-6.8) }\end{array}$ & 4.4 & $\mathrm{n} / \mathrm{a}$ & 5.8 & 5.7 & 6.1 & 5.3 & 5.0 \\
$\begin{array}{l}\mathrm{T} \text { (4, pmol/L (normal } \\
\text { range 12-22) }\end{array}$ & $\mathbf{5 . 5}$ & $\mathbf{1 1 . 2}$ & 13.7 & 14.3 & 15.1 & $\mathbf{1 1 . 6}$ & $\mathbf{1 0 . 3}$ \\
$\begin{array}{l}\mathrm{T} \text { TSH, } \mathrm{mU} / \mathrm{L} \text { (normal } \\
\text { range 0.27-4.2) }\end{array}$ & 2.71 & $\mathbf{0 . 0 8}$ & $\mathbf{0 . 0 2}$ & $\mathbf{0 . 0 2}$ & $<\mathbf{0 . 0 1}$ & $\mathbf{0 . 0 2}$ & $\mathbf{0 . 0 4}$ \\
$\begin{array}{l}\text { Levothyroxine dose } \\
\text { given, } \mathrm{Mg}\end{array}$ & 50 & 75 & 100 & 125 & 100 & 100 & 125 \\
\hline
\end{tabular}

$\mathrm{ACU}=$ ambulatory care unit; $\mathrm{T} 3=$ triiodothyronine; $\mathrm{T} 4=$ thyroxine; $\mathrm{TSH}=$ thyroid stimulating hormone.

calcium and vitamin D were normal. He was advised to undertake regular weight bearing exercise and will have a repeat DEXA after 2 years.

\section{Discussion}

Thyroid hormones are essential for growth, development and metabolism. The hypothalamic-pituitary-thyroid axis controls the production of thyroid hormones and works as a negative feedback system. The hypothalamus produces thyrotropin-releasing hormone which stimulates the anterior pituitary gland to release thyroid stimulating hormone (TSH) stimulating the thyroid gland to produce thyroid hormones $\mathrm{T} 3$ and T4. ${ }^{1}$

Hypothyroidism is the most common hormone deficiency with a $2 \%$ UK prevalence. ${ }^{1}$ Primary hypothyroidism, accounting for $95 \%$ of cases, is commonly due to autoimmune thyroid disease and presents with a low T4 and raised TSH. Central (or secondary) hypothyroidism results from pituitary or hypothalamic dysfunction causing insufficient stimulation of the thyroid gland. It presents with a low or normal TSH level and low T4 level. ${ }^{2}$

This patient presented with a normal TSH and low T4 indicating central hypothyroidism. His TFTs were misinterpreted and he commenced levothyroxine with no further investigations organised. National Institute for Health and Care Excellence

\section{Table 2. Pituitary hormones, August 2019}

\begin{tabular}{|c|c|}
\hline Cortisol, nmol/L & 22 \\
\hline Luteinising hormone, IU/L & $<0.1$ (normal range $1-9$ ) \\
\hline $\begin{array}{l}\text { Follicle stimulating } \\
\text { hormone, IU/L }\end{array}$ & 0.5 (normal range $1-12$ ) \\
\hline Oestradiol, pmol/L & $<92$ (normal range 95-223) \\
\hline Prolactin, IU/L & 250 (normal range $86-324$ ) \\
\hline Testosterone, $\mathrm{nmol} / \mathrm{L}$ & $<0.5$ (normal range 6.68-25.7) \\
\hline $\begin{array}{l}\text { Sex hormone binding } \\
\text { globulin, } \mathrm{nmol} / \mathrm{L}\end{array}$ & 175 (normal range 20.6-76.7) \\
\hline $\begin{array}{l}\text { Serum and urine } \\
\text { osmolarities, mOsm/kg }\end{array}$ & Normal (serum 394; urine 663) \\
\hline Sodium, mmol/L & 140 (normal range 136-145) \\
\hline Potassium, $\mathrm{mmol} / \mathrm{L}$ & 4.1 (normal range $3.5-5.1$ ) \\
\hline
\end{tabular}

guidelines recommend to "suspect secondary hypothyroidism if the clinical features are suggestive and T4 is low without raised TSH. ${ }^{3}$ He had progressive symptoms despite treatment for 9 months. Patients with central hypothyroidism often experience a delayed diagnosis due to solitary TSH measurement or TFT misinterpretation. ${ }^{4,5}$

Central hypothyroidism is rare, accounting for 1 in 1,000 UK cases of hypothyroidism. ${ }^{2}$ Central hypothyroidism presents as an isolated TSH deficiency or more commonly with other pituitary hormone deficiencies. ${ }^{6}$ In particular, it is fundamental to assess cortisol level prior to commencing levothyroxine replacement as commencing levothyroxine without appropriate steroid replacement can trigger an addisonian crisis. ${ }^{6}$

Patients with hypopituitarism present with non-specific symptoms. Table 3 indicates symptoms of hypopituitarism according to which hormone deficiency.

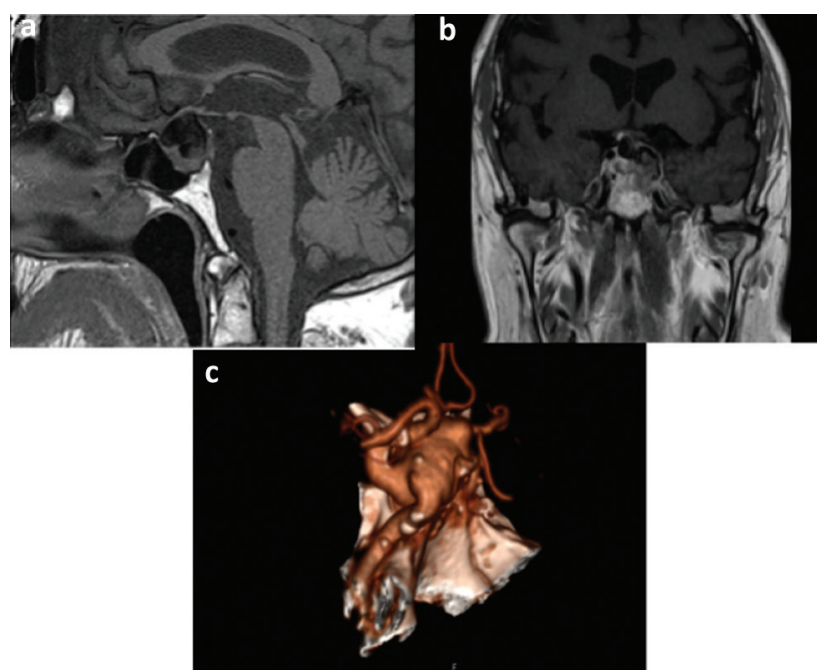

Fig 1. a) Sagittal plane computed tomography of the head; enlargement and remodelling of the bony fossa by a sellar, suprasellar and left parasellar lesion that is elevating the optic chiasm. b) Post-contrast T2 coronal plane computed tomography of the head; the laminar nature of the signal is suggestive of a vascular lesion. c) Computed tomography angiography; an angled, surface rendered model of the intracranial computed tomography angiography viewed from above showing a large, irregular aneurysm arising from an ectatic left cavernous carotid artery; the aneurysm is centred on the bony fossa and erodes the central skull base. 
Table 3. Common symptoms in individuals presenting with pituitary insufficiency ${ }^{6}$

$\begin{array}{lllll}\text { TSH } & \text { ACTH } & \text { Growth hormone } & \text { Gonadotrophin (male) } & \text { Gonadotrophin (female) } \\ \text { Lethargy/fatigue } & \text { Lethargy/fatigue } & \text { Decreased energy levels } & \text { Loss of libido } & \text { Loss of libido } \\ \text { Weakness } & \text { Weakness } & \text { Decreased wellbeing } & \text { Erectile dysfunction } & \text { Hot flushes } \\ \text { Cold intolerance } & \text { Myalgia } & \begin{array}{l}\text { Decreased muscle mass and } \\ \text { strength }\end{array} & \text { Decreased muscle mass } & \text { a-/oligo-menorrhea } \\ \text { Weight gain } & \text { Weight loss } & \text { Decreased bone mass density } & \text { Decreased bone mass density } & \text { Decreased bone mass density } \\ \text { Dry skin } & \text { Nausea/vomiting } & \text { Increased body fat / obesity } & \text { Testicular atrophy } & \text { Vaginal dryness } \\ \text { Constipation } & \text { Hypoglycaemia } & \text { Increased cardiovascular risk } & \text { Loss of body hair } & \text { Breast atrophy } \\ \text { Hoarseness } & \text { Postural } & \text { Long-term insulin resistance } & \text { Gynaecomastia } & \text { Premature atherosclerosis } \\ & \text { hypotension } & & \end{array}$

There are many causes of hypopituitarism. The most common is a pituitary adenoma or the resulting surgery and/or radiotherapy. Other important causes are pressure secondary to vascular lesions, which our patient presented with, and pituitary apoplexy. ${ }^{6}$

Hypopituitarism, after confirmation with biochemical testing, is investigated radiologically with MRI of the pituitary (or CT, if unavailable) to establish the cause. ${ }^{6}$

Intracranial aneurysms rarely cause hypopituitarism with a retrospective study identifying seven cases out of 4,000 hypopituitarism cases. All the patients identified had a visual field defect. Six of the seven had an aneurysm within the internal carotid artery, similar to this patient. Commonly, intrasellar cerebral aneurysms present with headaches prior to developing visual field defects. Less commonly, they may present with decreased visual acuity, endocrine derangement, hyponatraemia or cranial nerve palsies. ${ }^{7}$ Mass symptoms (such as headache, visual field defects or oculomotor palsies) are more common in giant ( $>25 \mathrm{~mm}$ ) aneurysms, as in this case, however, our patient did not have any symptoms secondary to mass effect nor a visual field defect. ${ }^{8}$

It is important to detect hypopituitarism secondary to an intracranial aneurysm given the morbidity and mortality associated with aneurysm rupture. Ruptured cerebral aneurysms cause $85 \%$ of non-traumatic subarachnoid haemorrhages (SAHs). They have devastating effects, with an estimated 30-day mortality of as high as $45 \%$, and $10 \%$ of patients dying prior to presentation to hospital. ${ }^{9}$ Patients who survive an SAH commonly have increased dependence, reduced quality of life and significant neurological complications. ${ }^{10}$

\section{Key points}

> Patients with central hypothyroidism often experience misdiagnosis and/or delayed diagnosis.

> It is vital to correctly interpret TFTs, especially given the overlap of symptoms and the utmost importance to replace steroid before levothyroxine if both deficiencies co-exist.

$>$ It is important to monitor TFTs when treating thyroid dysfunction and to review diagnosis if the TFTs pattern remains discordant.
> Intracranial aneurysms are a rare, yet important, cause of panhypopituitarism. It is vital to detect these to reduce morbidity and mortality.

\section{References}

1 National Institute for Health and Care Excellence. Hypothyroidism. NICE, 2020. https://cks.nice.org.uk/hypothyroidism

2 Persani L. Clinical review: Central hypothyroidism: pathogenic, diagnostic, and therapeutic challenges. J Clin Endocrinol Metab 2012;97:3068-78

3 Koulouri O, Gurnell M. How to Interpret thyroid function tests. Clin Med 2013;13:282-6.

4 Waise A, Belchetz P E. Unsuspected central hypopituitarism. BMJ 2000;321:1275-7.

5 Anyiam O, Cheung B, Al-Sabbagh S. Subclinical hypothyroidism or central hypothyroidism - The danger of thyroid function misintrepretation. Clin Case Rep 2018;6:1953-7.

6 Prabhakar VKB, Shalet SM. Aetiology, diagnosis and management of hypopituitarism in adult life. Postgrad Med J 2006;82:259-66.

7 Banerjee J, Khan SN, Elshatanoufy S, Singh M. Hypopituitarism secondary to unruptured intrasellar aneurysm misdiagnosed as pituitary adenoma: a case report. J IVF Reprod Med Genet 2014;1:3.

8 Ferndadez JM. Giant intrasellar aneurysm presenting with panhypopituitarism and subarachnoid hemorrhage: case report and literature review. Clin Investig 1994;72:302-6.

9 Chan V, Lindsay P, McQuiggan J et al. Declining admissions and mortality rates for subarachnoid hemorrhage in Canada Between 2004 and 2015. Stroke 2019;50:181-4.

10 Dimopoulou I, Kouyialis AT, Tzanella M et al. High incidence of neuroendocrine dysfunction in long-term survivors of aneurysmal subarachnoid hemorrhage. Stroke 2004;35:2884-9.

Address for correspondence: Dr Emma Mullarkey, Chelsea and Westminster Hospital, 369 Fulham Road, Chelsea, London SW10 9NH, UK.

Email: emma.mullarkey@nhs.net 